\title{
Development of Electronic Educational Resources for Physics with Elements of Augmented Reality Technology
}

\author{
https://doi.org/10.3991/ijim.v14i13.13475
}

\author{
Yevgeniya Daineko ${ }^{(凶)}$, Madina Ipalakova, Dana Tsoy \\ Aigerim Seitnur, Zhandos Baurzhan, Ersultanbek Elgondy \\ International Information Technology University, Almaty, Kazakhstan \\ yevgeniyadaineko@gmail.com
}

\begin{abstract}
The paper presents the work on the educational mobile application based on the Unity game engine using the Vuforia platform. The appropriate research on electronic educational resources and augmented reality (AR) technology was conducted. The authors also studied real world experiences in the use of the technology in various fields of its application, in education in general, and in physics in particular. As an outcome of the work, an electronic educational resource for secondary educational institutions was developed. It was implemented as an application for virtually conducting laboratory work in physics using AR.
\end{abstract}

Keywords - Electronic educational resource, mobile application, augmented reality, Leap Motion, Unity3D, Vuforia, physics.

\section{Introduction}

The educational possibilities of modern information and communication technologies and their application in practice, is one of the current directions of pedagogy. The application of information technology in education by specialists in Kazakhstan can be described as widespread, alongside well-equipped computer classes in schools, universities, and other institutional and educational organizations. In this regard, there is an urgent need to create new teaching methods that use information technologies, as well as software tools and systems that implement these methods. Among them, it is worth highlighting the technology of augmented reality, which can change the nature of the learning process, motivate students, improve the quality of education, and immerse students in the informational and educational environment.

The primary goal of this project is to develop a virtual physical laboratory, with a set of laboratory experiments in physics for their use in secondary school physics lessons. Physical processes and phenomena studied within the laboratory are accompanied by three-dimensional visualizations using AR. This allows users to immerse themselves in the learning environment, thus engendering better understanding of the physical laws being examined. Education in the form of games made possible by the use of AR will increase students' interest in the subject. It is well-known that physics is the study of the processes taking place in the material world around us and the laws that describe these processes. Therefore, for better student understanding, the need for the real-world 
simulations of these processes, and a clear demonstration of the principles of operation of certain devices involved in physical experiments comes to the fore. Thus, it is necessary to show students how such devices and physical laws of the world work. A prerecorded experiment or a 'non-interactive' simulation of an experiment can easily accomplish the objectives of this task. However, it is fundamentally important in the proposed approach, to provide students with the opportunity to independently influence the course of the experiment. Thus, the practical significance of this project becomes apparent. Using the proposed training tool, the student will become a direct participant in the process being studied, which is an undeniable advantage of this approach and one of the fundamental factors of effective learning.

\section{E-Learning and E-Learning Resources}

The term, 'e-learning', came into use in the mid-1990s along with advances in the World Wide Web. E-learning concentrates on several objectives, the first being to create classrooms independent of time and place via the use of information and communication technology. It is described in terms of form and structure as an electronically transmitted synchronous and asynchronous cooperation, aimed at confirming and constructing knowledge. The technological structures for e-learning are the Internet and other related communication platforms. The two key modes of e-learning are online and blended learning. The main difference between them is the independent learning format provided by the former, and the high level of interaction afforded by the latter. Fully online learning is an independent form of distance education that originated separately from the mainstream or widely accepted understanding of distance education. On the other hand, blended learning in educational organizations is the most widespread form of e-learning.

As mentioned above, e-learning is not a type of distance teaching that is automated. E-learning is the first and guiding element in schools and universities that provide a quality instructional experience. At the same time, e-learning can also allow for online teaching in virtual classrooms, which has developed from a different interpretation of how to position e-learning in the practice landscape. Distance has now become a relatively small functional limitation in offering a highly interactive, skilled teaching experience. In terms of distance education, e-learning symbolizes a complete paradigm shift from traditional learning approaches [1].

E-learning represents an innovative branch of education with its key technology and dynamic teaching and learning strategies. The shift in pedagogical presumptions and methods reflected in both e-learning and theoretical exercises represents a completely fresh era of distance schooling. Online teaching in virtual classrooms demonstrates the post-industrial growth of remote teaching, and integrates flexibility (asynchronous Internet communication) with interaction (connectivity), addressing the space and time constraints in a way that enhance the benefits of higher education [2]. Specifically, the advantages of online teaching extend beyond input data instruments and technology.

At the same moment, we must not overlook the boundless importance of face-toface participation in schooling in order to fully integrate e-learning into the 
development of formal and higher education. The ability to combine interactions online and face-to-face integrates the unique advantages of each mode, meeting the objectives of traditional educational organizations, while recognizing and incorporating the enormous potential of online teaching. Thus, e-learning is a mixed form of teaching that integrates the best of online and face-to-face teaching characteristics.

\section{$3 \quad$ Augmented Reality in Education}

Due to the ability of smartphones to deliver engaging AR experiences, the mobile industry is fostering the continuous production of new applications with AR and virtual reality (VR) features, which are exploring the limits of this new flagship technology. Furthermore, the potential for employing AR in educational smartphone applications is beginning to be fulfilled on a global basis. Research shows that the appeal of AR is widespread and not restricted only to young audiences or niche educational needs [3, 4]. Fundamental concepts in a broad range of subject areas can be taught in exciting and engaging ways that were not possible before the advent of AR as a technological breakthrough.

AR is currently being used widely in education. It is an innovation that combines advanced technology with data from genuine physical situations, allowing clients to interact with virtual items and view the physical conditions at the same time via a tablet or mobile phone camera [5]. Thus, it enables clients to collaborate with both virtual and real objects. Consequently, the opportunities presented by AR are essentially unique.

It is often challenging to develop new teaching methods based on innovative technologies in education. To ensure a smooth learning process, direct involvement in the teaching process should be carefully planned. Currently, virtual laboratories independent of the domain of applications are beginning to be successfully implemented in the educational process, especially for natural sciences.

Physics is the science of the natural world that forms the basis for other natural sciences. Obviously, learning physics consists of both theory and practice, which is represented by laboratory work, or labs. During labs, students apply previously acquired theoretical knowledge. Such laboratory work focuses on performing experiments on particular topics in most cases. It allows learners not only to conduct experiments, but also to determine observational goals, state hypotheses, evaluate results, and produce reports that encompass all of these stages. The most difficult task is to incorporate software with the elements of AR into existing curricula to aid students in fully understanding physical experiments. Along with traditional forms of education, the primary goal of adopting modern computer innovations is to enhance the quality of education.

Positive shifts in observing various physical phenomena have been revealed by existing projects; for instance, a research article entitled, "Using virtual laboratories in teaching natural sciences: An example of physics courses in university" [6]. Through this research, the authors demonstrate how to integrate specific software artifacts into existing curricula to support students at universities in studying natural science disciplines like physics. The program is premised on virtual lab ideas, while the implementation is built on Microsoft, 3D Modeling and the .NET XNA Framework. Another 
relevant article was published at the $12^{\text {th }}$ International Conference on Electronics Computer and Computation (ICECCO) entitled, "Implementing physics virtual laboratory in 3D: An example of Atwood machine" [7]. The research includes the theoretical basis for physical experiments, and centres upon a description of an Atwood machine in the scope of this work, and the detailed explanation of the creation of a virtual laboratory. It also is worth mentioning the use of AR for studying physics on the topic of Electromagnetism [8].

Due to some advantages over traditional laboratories, their virtual counterparts have become a vital part of the successful and modern teaching environment, because more students can access them easily and costs are reduced. The paper, "Virtual laboratories in engineering education: The simulation lab and remote lab" breaks down the main problems and recent trends in virtual laboratories, namely simulation, environmental laboratories and remote laboratories via the Internet for collaborative learning [9].

Virtual labs are a vital digital tool. In science teaching, virtual laboratories can be very helpful, especially in situations where:

- The experimental practices to be performed quickly and cannot be easily observed or implemented safely

- The experimental process is indeed very slow and/or complicated and is not compatible with the accessible teaching time

- The experiments include risks to learners' health and physical safety

- The learning activities demand modeling.

Students are granted a tool to experience the phenomena at hand independent of the constraints of time and space, which makes representations on a computer screen within virtual laboratories substantially advantageous over comparable real-life experiences. They are accessible throughout the year, unlike school laboratories, which are restricted to one place and for limited periods of time [10]. Learning with AR allows students to acquire more advanced abilities in using computers, which can be regarded as lifelong learning skills. The use of such technologies also brings together a wide range of topics and offers great assets for more inclusive sessions [11].

\section{Tools}

Unity3D is a cross-platform game engine. It allows the recreation of the realistic interaction of objects due to physical calculations from Nvidia. This is one of the main advantages of the game engine. In addition, objects in Unity are subject to fine-tuning. For example, a rigid body can have various configurations of characteristics, since they can be easily configured directly from the game engine window, which also simplifies the work and makes the user experience more convenient. The editor has an object inheritance system, in which child objects will repeat all changes in the position, rotation and scale of the parent object. Scripts in the editor are attached to objects as separate components.

Unlike many game engines, Unity has two main advantages in the visual development environment and cross-platform support. The first factor includes visual modeling 
tools, an integrated environment and an assembly chain, which is aimed at increasing the productivity of developers in the stages of prototyping and testing. In cross-platform support, places of deployment are provided (i.e. installation on a personal computer, mobile device, console, etc.), along with development tools (i.e. the integrated environment can be used in Android and iOS).

Vuforia is a robust image tracking platform offering several image tracking varieties and $3 \mathrm{D}$ objects in real time. The image tracking platform offers greater user liberty to operate with minimal loss of monitoring [12]. The image is tracked by the smartphone camera. The gap between the lens and image and the difference of the image is calculated by Vuforia. It is used in the superimposition of virtual items in a scene [13]. When the images used for tracking are identified, the virtual elements associated with them will be shown. The virtual items will vanish when the monitoring of these images stops. The monitoring of images is incorporated straight into Unity.

In laboratory work, a variety of tools are needed in order to conduct an experiment. Therefore, the user should be able to manipulate each object separately. It can be achieved using multiple image targets, which are the images that Vuforia can detect and track. The Vuforia Library allows tracking of up to 100 image targets simultaneously.

\section{$5 \quad$ Results}

The developed application provides access to a set of physical laboratory experiments, such as "The study of Ohm's law for a circuit part", "Dependence of the body flight distance on the throw angle", "Determination of the moment of inertia of a ball", "Study of series-parallel connecting conductors" and "Determination of the EMF of the current source and its internal resistance". These examples are taken from the physics course for the 10th grade of secondary schools in the education system of Kazakhstan.

The application allows students to complete all of the laboratory work independently, because it features the corresponding theory, as well as the experiment itself in AR mode.

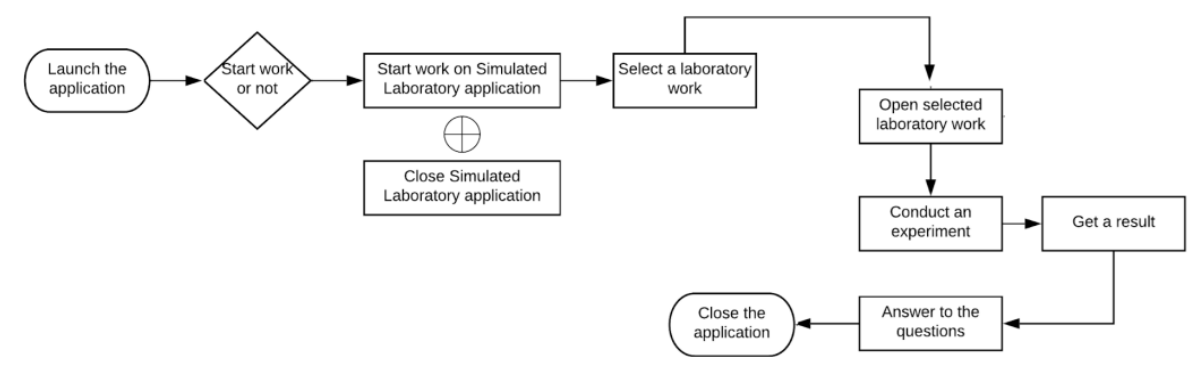

Fig. 1. Use Case diagram of the application

Fig. 1 demonstrates a use case diagram, which describes the steps that should be taken in order to complete the interaction between a user and the application. Thus, the first step is to launch the application, then choose the experiment and conduct it. After 
completion, the user receives a result and can answer the questions on the topic of the laboratory work.

By way of example, "The study of Ohm's law for a circuit part" is presented below. The purpose of the experiment is to establish the dependency between current, resistance and voltage. The following equipment is given: an ammeter, a voltmeter, and resistors of 100, 200 and $300 \mathrm{Ohm}$. The task of the laboratory work is to use different resistors and to observe how the voltage changes.

The application works based on the aforementioned Vuforia platform, which operates with several markers simultaneously. The scheme that needs to be built, is attached to one of the markers and demonstrates the real circuit that is shown in Fig. 2.

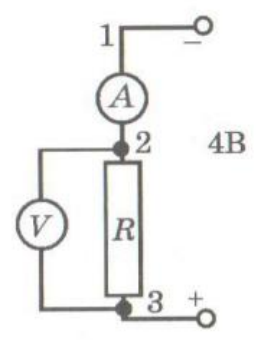

Fig. 2. The scheme of the circuit

In Fig. 3 there is a demonstration of the scheme that is attached to the one of the markers, and the complete installation with all the markers and equipment in place. It is also shown that the users can see the value of the current and compare it with their own calculations. This calculation is done by using the following formula, where I is current, $\mathrm{U}$ is voltage and $\mathrm{R}$ is resistance:

$$
I=\frac{U}{R}
$$
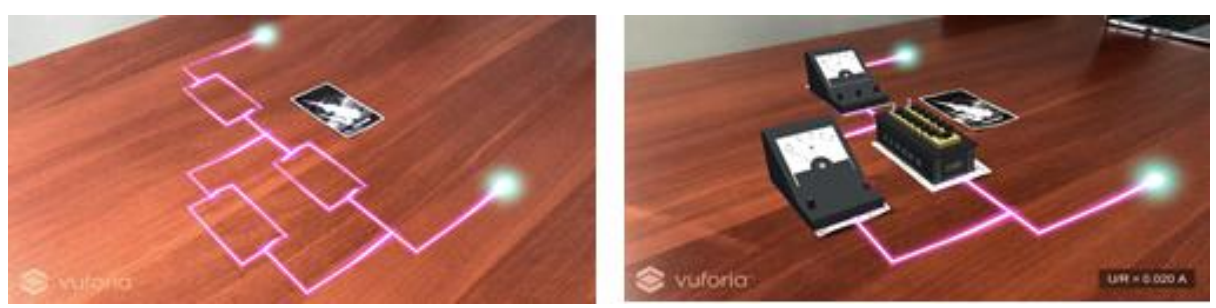

Fig. 3. Demonstration of the laboratory work

The user interface of the current application has three main characteristics: clarity, attractiveness, and responsiveness. Clarity means that the user interface is designed in such a way that allows users to easily interact with the application. Users are always aware of the status of the application. Responsiveness means how fast the system responds. It is important to emphasize that real-time rendering of virtual objects adds 
extra loads onto the CPU, so this may seem a bit slower than expected. Responsiveness is also associated with feedback. Therefore, the system "communicates" with the user by providing information about what is happening under the hood. Finally, attractiveness means that the interface is aesthetically pleasing.

\section{Conclusion}

Many international researchers have identified AR as one of the most anticipated trends in education for the coming decade, so domestic universities and schools should not stand aside. Today, AR technologies in education are at the formative stage, which involves analyzing existing international and domestic experience. Hence, it is necessary to actively implement them in educational processes at all levels.

Thus, the authors have developed a software application using augmented reality for secondary schools. It works on smartphones with Android and iOS platforms. The application consists of a set of laboratory experiments conducted in augmented reality mode. The user interface is presented in Kazakh, Russian and English with each experiment containing instructions and manuals, which feature the purpose of the work, theoretical material, experimental setup, work order and report.

The application was introduced into the educational process in several schools in Almaty, Kazakhstan, at the beginning of the 2019-2020 academic year. The initial feedback that the authors have received from teachers is that the application is very useful, especially in the current situation, when all the schools in the country have shifted to distance learning due to the Coronavirus pandemic.

\section{$7 \quad$ Acknowledgement}

The work was done under the funding of the Ministry of Education and Science of the Republic of Kazakhstan (No. AP05135692).

\section{$8 \quad$ References}

[1] F. Rennie and T. Morrison, e-Learning and Social Networking Handbook Resources for Higher Education, 2nd ed. New York: Routledge, 2013.

[2] N. Manouselis, R. Vuorikari and F. Van Assche, "Collaborative recommendation of e-learning resources: an experimental investigation", Journal of Computer Assisted Learning, vol. 26, no. 4, pp. 227-242, 2010. Available: https://doi.org/10.1111/j.1365-2729.20 $\underline{10.00362 . x}$

[3] M. Bower, C. Howe, N. McCredie, A. Robinson and D. Grover, "Augmented Reality in education - cases, places and potentials", Educational Media International, vol. 51, no. 1, pp. 1-15, 2014. Available: https://doi.org/10.1080/09523987.2014.889400

[4] Z. Merchant, E. Goetz, L. Cifuentes, W. Keeney-Kennicutt and T. Davis, "Effectiveness of virtual reality-based instruction on students' learning outcomes in K-12 and higher educa tion: A meta-analysis", Computers \& Education, vol. 70, pp. 29-40, 2014. Available: https://doi.org/10.1016/j.compedu.2013.07.033. 
[5] P. Milgram, H. Takemura, A. Utsumi and F. Kishino, "Augmented reality: a class of displays on the reality-virtuality continuum", Telemanipulator and Telepresence Technologies, 1995. Available: https://doi.org/10.1117/12.197321

[6] Y. Daineko, V. Dmitriyev and M. Ipalakova, "Using virtual laboratories in teaching natural sciences: An example of physics courses in university", Computer Applications in Engineering Education, vol. 25, no. 1, pp. 39-47, 2016. Available: https://doi.org/10.1002/cae. 21777.

[7] V. Dmitriyev and Y. Daineko, "Implementing physics virtual laboratory in 3D: An example of Atwood machine", 2015 Twelve International Conference on Electronics Computer and Computation (ICECCO), 2015. Available: https://doi.org/10.1109/icecco.2015.7416 $\underline{891}$

[8] S. Techakosit, Somsak and N.Prachyanun, "Using Augmented Reality for Teaching Physics”, 2015

[9] B. Balamuralithara and P. Woods, "Virtual laboratories in engineering education: The simulation lab and remote lab", Computer Applications in Engineering Education, vol. 17, no. E. Zotou, "Innovative education: Virtual labs", Open Schools Journal for open science, 2019. [Online]. Available: https://ejournals.epublishing.ekt.gr/index.php/openschoolsjournal/article/view/17377/17679. [Accessed: 7- Dec- 2018]. https://doi.org/10.12681/osj.173 $\underline{77}$

[10] B.tselfes,"trial and error: the workshop on the teaching of science", athens: island. Education and training sector (tek). Training material for teacher training - issue 5: sector pe04. Cti, 2002 available from electronics address: http://axis.teikav.edu.gr/pake/Enotita_7_Logismika_PE04/AMAP_Anoikto_Mathisiako_Perivallon / AMAP-Intro.pdf

[11] D. Amin and S. Govilkar, "Comparative Study of Augmented Reality Sdk's", International Journal on Computational Science \& Applications, vol. 5, no. 1, pp. 11-26, 2015. Available: https://doi.org/10.5121/ijcsa.2015.5102.

[12] B. Delail, L. Weruaga and M. Zemerly, "CAViAR: Context Aware Visual Indoor Augmented Reality for a University Campus", 2019. https://doi.org/10.1109/wi-iat.2012.99

\section{Authors}

Yevgeniya Daineko, Madina Ipalakova, (m.ipalakova@gmail.com), Dana Tsoy (danatsoy@gmail.com), Aigerim Seitnur, (aigerim.seitnurova@mail.ru), Zhandos Baurzhan, (zhandos.baurzhan@gmail.com), Ersultanbek Elgondy, (ersultan_elgondin@mail.ru), all are from International Information Technology University, Almaty, Kazakhstan.

Article submitted 2020-01-30. Resubmitted 2020-03-25. Final acceptance 2020-03-29. Final version published as submitted by the authors. 